\title{
IMMUNOGLOBULIN M (IGM) NEPHROPATHY IN CHILDREN - REPORT OF TWO CASES
}

\begin{abstract}
AFROZ S ${ }^{1}$, SIMI MA ${ }^{2}$, SHARMIN $\mathrm{S}^{3}$, YEASMIN L ${ }^{4}, \mathrm{KUNDO} \mathrm{LC}^{5}$
Abstract

Immunoglobulin $M$ nephropathy (IgMN) is an idiopathic glomerulonephritis characterized by a variable degree of mesangialhypercellularity and diffuse IgM deposits.Patients usually presents with refractory nephrotic syndrome (NS) and hematuria. We present two patients with IgM nephropathy one with frequently relapsing NS with steroid dependence, treated with oral steroid and cyclophosphamide subsequently with tacrolimus. The patient showed complete remission but breakthrough relapses occurredduring the course of steroid treatment.The second case presented with persistentgross hematuria and nephroticrange proteinuria for 6 months. The patient showed complete remission of proteinuria and hematuria with oral steroid andremained on remission for 9 months. Then again developed hematuria \& proteinuria and subsequently showed response to oral steroid and cyclphosphamide. Renal histopathology \& immunofluorescence study of first case revealed normal mesangial cellularity and basement membrane thickness with mesangial deposits of IgM. Second case showed global mesangial proliferation with increasing mesangial matrix with moderate mesangial deposits of IgM.
\end{abstract}

Key words: IgM nephropathy, children.

J Dhaka Med Coll. 2014; 23(1) : 131-133.

\section{Introduction}

Immunoglobulin $\mathrm{M}$ nephropathy (IgMN) is an idiopathic glomerulonephritis characterized by a variable degree of mesangial hypercellularity and diffuse IgM deposits ${ }^{1}$.The pathogenesis of IgM nephropathy remains unclear. Some have suggested abnormal Tcell function or a disturbance in immuneaggregate clearance by mesangial cells ${ }^{1}$. However, many reports have demonstrated increased steroid resistance and lessfavorable outcome in IgMN compared with minimal change disease (MCD) and thus, consider it as a distinct clinic-pathological entity ${ }^{1}$.Very few reported cases or data have been published regarding IgMN. The management and prognosis of the disease still remain enigmatic. In view of these situation two cases of IgM nephropathy is reported here.

\section{Case report:}

Case 1:

A 7 year old girl, presented with nephrotic syndrome initial attack at the age of 3 years. The nephrotic syndrome was initially steroid responsive but progressively she became steroid dependant and developed steroid toxicity. Initially she was normotensive but later became hypertensive. Urine analysis revealed no hematuria, no cast. Her renal function, complement C3 \& C4 were normal;

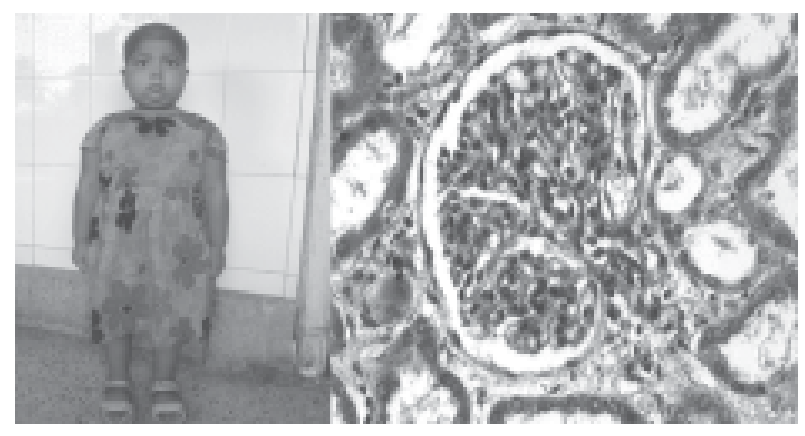

1. Dr Shireen Afroz, Associate Professor, Dept. of Paediatric Nephrology, Dhaka Medical College Hospital, Dhaka.

2. Dr. Maliha Alam Simi, Registrar, Dept. of Paediatrics, Dhaka Medical College Hospital, Dhaka.

3. Dr. Shanjida Sharmin, Assistant Registrar, Dept. of Paediatrics, Dhaka Medical College Hospital, Dhaka.

4. Dr. Laila Yeasmin, Assistant Professor, Dept. of Paediatric Nephrology, National Institute of Kidney Diseases \& Urology (NIKDU), Dhaka.

5. Dr. L. C. Kundu, Assistant Professor, Dept. of Paediatric Nephrology, Faridpur Medical College Hospital, Faridpur.

Correspondence: Dr. Shireen Afroz, Associate Professor, Dept. of Paediatric Nephrology, Dhaka Medical College Hospital, Dhaka. 
ANA and anti-ds DNA were negative. Ultrasonography report revealed normal findingswith normal kidney sizes according to age.

Renal histopathology on light microscopy revealed normal glomeruli with normalmesangial cellularity and basement membrane thickness. But direct immunofluorescence microscopy demonstrated mild mesangial deposits of IgM.

She was treated initially with only steroid and responded well; subsequently with cyclophosphamide as she developed steroid dependence and finally with tacrolimus and oral steroid for the last two years. The patient showed complete remission but breakthrough relapses occured during steroid tapering and remained on remission at $1 \mathrm{mg} / \mathrm{kg}$ of oral prednisolone along with tacrolimus for the last 2years. Now she is on follow up.

\section{Case 2:}

A 5 year old boy of non-consanguineous parents with no significant past history presented with gross hematuria and proteinuria for 6 months. There was no history of passage of blood clot, gravel or stone through urine and not preceeded by respiratory tract infection. He had no difficulty in micturition or contact with tuberculosis patient.His elder brother died of chronic kidney disease at 18 year of age. There was no family history of hematuria, deafness or visual problem.

Clinically he was playful, mildly pale, afebrile, normotensive, moderately edematous, mildly stunted, no skin rash and bleeding spot, hearing and vision were intact. Urine colour was red, dipstick and boiling test revealed moderate proteinuria. There were ascites but no organomegaly was found.

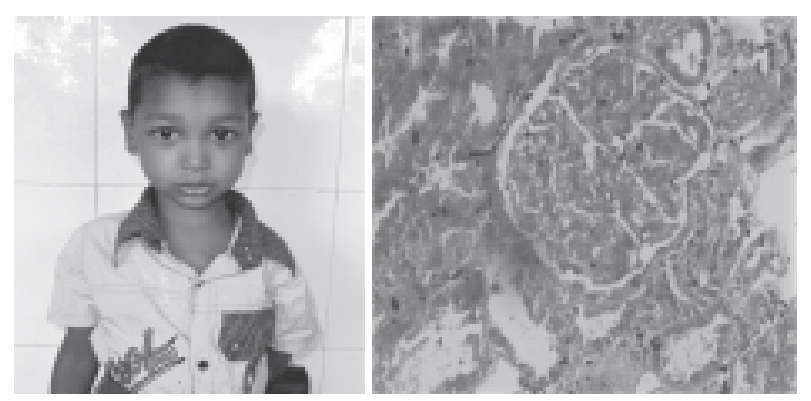

His $\mathrm{Hb} \%$ was $10.6 \mathrm{gm} / \mathrm{dl}$, Urine R/M/E showed plenty of RBC, no cast, sterile urine culture and urine phase contrast microscopy revealed $20 \%$ dysmorphic RBC. His spot urine protein creatinine ratio was 2 . Light microscopic featureof renal histopathology showed mild to moderate degree of global proliferation of mesangial cell with increased mesangial matrix. On direct immunofluorescence microscopy, moderate mesangial deposits of immunoglobulin M (IgM) was present. He was treated with Prednisolone for 3 months $(2 \mathrm{mg} /$ $\mathrm{kg}$, daily for $6 \mathrm{wks}$ and $1.5 \mathrm{mg} / \mathrm{kg}$, alternate day for $6 \mathrm{wks})$. Proteinuria disappeared within 14 days and hematuria disappeared after $4 \mathrm{wks}$ of treatment.He remained on remission for 9 months. There after he again developed proteinuria and gross hematuria following an episode of viral fever. After 2 weeks proteinuria subsided spontaneously after remission of fever but mild to moderate hematuria was still persisting. He again developed gross hematuria and proteinuria 15 months later and showed response to oral steroid and cyclophosphamide. Now he is on regular follow up.

\section{Discussion}

IgM nephropathy (IgMN) is an idiopathic glomerulonephritis with mesangial deposition of IgM.It is an important and rather neglected pathology responsible for renal morbidity in children and adults in developing countries as compared to the developed nations with incidence of $2-18.5 \%$ of native biopsies ${ }^{2}$. IgMN is a relatively less recognized clinicoimmunopathological entity in the domain of glomerulonephritis, often thought to be a bridge between minimal change disease and focal segmental glomerulosclerosis ${ }^{2}$. IgM nephropathy can present as nephrotic syndrome or less commonly with subnephrotic proteinuria or rarely hematuria. About 30\% patients respond to steroids whereas others are steroid dependent or resistant. The disease may remain silent for a long period but it is progressive.Among the described two cases, first one became steroid dependent, maintaining remission with tacrolimus and oral steroid at a high dose, but the second case is still steroid sensitive and showing slow progression with persisting hematuria. A study 
of 110 patients with 15 year follow-up showed that $22.7 \%$ progressed to end-stage renal disease with another $13.7 \%$ manifesting renal insufficiency; half of the patients became hypertensive ${ }^{3}$. IgM nephropathy was first described in 1978, in a series of 12 cases whose initial native renal biopsy specimens displayed mild glomerular mesangialhypercellularity on light microscopy, diffuse granular mesangial IgM deposition on immunofluorescence examinationandin whom systemic disease and other glomerulonephritides were excluded ${ }^{4}$. In our cases, mild mesangial deposits of IgM was found in first case without any other changes and in second case global mesangial proliferation with moderate mesangial deposition of IgM was found.IgMN is a relatively common and still debatable entity in the list of glomerulopathies, presenting with Idiopathic nephrotic syndrome, isolated haematuria or combined haematuria and asymptomatic proteinuria in both adults and children ${ }^{5}$. Its extreme forms resemble two previously well described entities of minimal change disease (MCD) and focal segmental glomerulosclerosis (FSGS) ${ }^{5}$. With the use of steroid long term remission of proteinuria was achieved in only $14 \%$ of patients, indicating need for a more effective treatment ${ }^{6}$. A study of two cases of IgMNshowed response to combination therapy of reduced dose of rituximab followed by mycophenolate mofetil ${ }^{6}$. The disease may remain silent for long period, however, it is progressive. Some authors also had reported worse prognosis in IgM nephropathy compared to $\mathrm{MCD}^{7}$.

\section{Conclusion}

It can be concluded that this form of nephropathy constitutes a distinct entity separate from minimal change disease. Patients with IgMN had a higher prevalence of steroid dependence.

\section{References}

1. Mokhtar GA. IgM nephropathy: clinical picture and pathological findings in 36 patients. Saudi $J$ Kidney Dis Transplant 2011; 22(5): 969-75.

2. Vanikar A. IgM nephropathy; can we still ignore it. J Nephropathol 2013; 2(2): 98-103.

3. Myllymaki J, SahaH,Mustnen J, Helin H, Pasternack A. IgM nephropathy: clinical picture and long term prognosis. Am J Kidney Dis 2003; 41(2): 343-50.

4. Salmon AHJ, Kamel D, Mathieson PW. Recurrence of IgM nephropathy in a renal allograft. Nephrol Dial Transplant 2004; 19: 2650-2.

5. Shakeel S, Mubarak M, Kazi JI, Lanewala A. the prevalence and clinicopathological profile of IgM nephropathy in children with steroid-resistant nephrotic syndrome at a single centre in Pakistan. J Clin Pathol 2012; 10: 1136.

6. Jin'ai G, Yonghui X, Jianhua M, et al. Rituximab followed by mycophenolatemofetil in children with IgM nephropathy. J Indian Pediatr 2012; 49(10): 831-3.

7. Zeis PM, et al. Glomerulopathy with mesangialIgM deposits: long-term follow up of 64 children. Pediatric Int 2001; 43(3): 287-92. 